\title{
Relationships between type and longevity in the Holstein breed
}

\author{
Hélène LARroquE* ${ }^{*}$ Vincent DUCRocQ \\ Station de génétique quantitative et appliquée, \\ Institut national de la recherche agronomique, \\ 78352 Jouy-en-Josas Cedex, France
}

(Received 18 October 1999; accepted 31 August 2000)

\begin{abstract}
The relationship between type traits and longevity was studied in the French Holstein breed using a survival analysis model. In this model, the phenotypic value adjusted for systematic fixed effects, the estimated breeding value, or the residual value (defined as the difference between the adjusted phenotypic value and the estimated breeding value) of the cow for each type trait was included as a risk factor. This was done separately for two subpopulations (registered and nonregistered herds) and with or without adjustment for production traits, i.e., considering true or functional longevity. For both types of herds, udder traits (and above all, udder depth) clearly influenced the length of productive life. There seemed to be a more pronounced voluntary culling on type traits in registered herds. The correction for the within herd-year class of production traits, as a way to approximate functional longevity, increased the importance of udder traits and decreased the weight of capacity traits. The same results were obtained when the phenotypic value of the cow for type was replaced by her estimated breeding value, whereas residuals had little impact. The relationship between longevity and type traits was most often nonlinear, in particular for udder traits, but in this study, no trait with a clear intermediate optimum was found.
\end{abstract}

longevity / type traits / survival analysis / nonlinearity / dairy cattle

\section{INTRODUCTION}

The stayability of a cow in her herd is frequently conditioned by her morphology. Consequently, type traits are often presented as good predictors of longevity: type scoring is usually performed during the first lactation, which brings early information on survivability. To get reliable direct evaluations of sires for longevity of their daughters, waiting for the actual culling of a minimum number of daughters is needed, which may take too long to be useful in breeding programs. For all these reasons, it seems appropriate in genetic evaluations to combine direct longevity information with indirect information on early predictors such as type traits. This requires both a proper choice of the

\footnotetext{
* Correspondence and reprints

E-mail: Helene.Larroque@dga.jouy.inra.fr
} 
type traits to be used as early predictors and a precise knowledge of the genetic relationship between these and longevity [12]. Only the former aspect will be considered here. An important component of this is the correct assessment of the phenotypic impact of type traits on culling. This was studied here in the French Holstein breed, with a focus on two main questions:

- Is the risk of being culled due to poor type characteristics the same in the whole French Holstein population?

In North America and some other countries, the fact that an animal belongs or not to the official herdbook has a strong effect on culling policy: registered cows are better valued because they may be sold for breeding purposes and not for dairy production only. They are often kept in the herd longer [5]. They are less frequently voluntarily culled for low milk production and more frequently for body characteristics $[14,15]$. This fact explains why the analyses of the relationship between type and longevity are often performed separating the two (registered and grade). subpopulations [2,4,15]. For registered cows, type traits regularly appear as a source of voluntary culling, similar to production traits, and no longer as a predictor of involuntary culling [11].

In France, the herdbook association of the Friesian breed was replaced, on December 30, 1974 by an association in charge of breed promotion (UPRA: Union de Promotion de la RAce). This system is more open because breeders voluntarily subscribe to a service with a systematic yearly visit for the type scoring of all first lactation cows. They can quit at any time. In other words, registration is herd-based, not animal-based. However, registered herds are often elite herds. Then, the two subpopulations (UPRA / NON UPRA) should be compared with respect to the attitude towards culling on type traits.

- Is the relationship between type traits and longevity linear?

For some traits, a reasonable assumption might be that the more extreme a type trait, the higher (or the lower) the culling risk. But for others, the relationship may be more complex: for example, some traits may have an intermediate optimum, with an increased culling risk when type score gets farther away from this optimum; or a score above a certain threshold may be considered as satisfactory and then, the corresponding trait does not influence longevity at all, because it is no longer related to culling reasons.

Ducrocq [7] used survival analysis to assess the influence of type traits on longevity on registered and grade Holstein cows in the USA: the impact of the inclusion of each type trait to a survival model without any genetic component (no sire effect) was examined. Similar studies have been carried out in homogeneous populations [3,10,16-18].

To answer the two questions above in the case of the French situation, the approach of Ducrocq [7] was applied to the French Holstein data set and extended in several ways. In this study, three different aspects were examined:

1. The populations, separating registered herds, denoted as UPRA herds, and other herds, NON UPRA;

2. the longevity traits, distinguishing between "true longevity" (without correction for milk production) and "production adjusted longevity", as an approximation of functional longevity; 
3. the way the animal's type is described in the model as a (adjusted) phenotype or as its components (estimated breeding value (EBV), or residual of the genetic evaluation model) in order to check whether a better within-herd environment leading to a better type influences longevity as much as a better genotype.

\section{MATERIALS AND METHODS}

Type data from Holstein cows scored between October 1992 and October 1997 was combined with survival information on all cows milk recorded for the same herds during the same period.

All analyses were performed using the "Survival Kit-V3.0" [8].

\subsection{Materials}

\subsubsection{Selection of herds}

Registered (UPRA) herds were defined as herds with at least one systematic type classification of first lactation cows by UPRA classifiers. For the others (NON UPRA), type scores originated from first crop daughters of young sires as well as herdmates scored at the same time (in order to define contemporary groups in the genetic evaluation). This difference in the recording system led to distinct editing criteria in the two subpopulations:

- The nonregistered (NON UPRA) file included nonregistered herds with more than 20 cows and with at least 10 type scored cows at a minimum of 4 distinct dates during the whole period. The type scored animals had to represent at least $18 \%$ of the total number of animals in the herd. As a result, 2165 herds were selected, with 209644 cows and 57090 type scored cows.

- The registered (UPRA) file contained data from registered herds with more than 20 cows, with at least 40 type scored cows in a minimum of 5 classification rounds during the whole period. $60 \%$ or more of the cows in the herd had to be classified. In total, this file included 1242 herds with 151741 cows and 103983 having type information.

\subsubsection{Data}

The measure used for longevity was length of productive life (LPL) defined as number of days since first calving. All records on animals calving before October 1st 1992 were left truncated. Animals still alive on October 1st 1997, or sold to other farms, were right-censored.

For each type scored animal, information on traits were extracted from the routine multiple trait animal model evaluation [6] i.e.,

- the cow's estimated breeding value $\hat{g}$;

- the estimated residual part of the linear model used in evaluation $\hat{r}$;

- the phenotype $\hat{p}$ adjusted for systematic environmental effects (stage of lactation, age at first calving, herd-round-classifier effects). In fact, $\hat{p}=\hat{g}+\hat{r}$. This adjustment was necessary in order to objectively compare type information obtained in different environments or at different stages of the animal's life. 
Phenotypic scores have very different variabilities and were standardised and expressed in corresponding genetic standard deviations. Then, they were grouped into classes of equal width (arbitrarily taken equal to 0.2 genetic standard deviation), except for extreme categories. This standardisation resulted in 21 classes for estimated breeding values (from $-1.9 \sigma_{g}$ to $+1.9 \sigma_{g}$ ), 31 for estimated residuals (from $-2.9 \sigma_{g}$ to $+2.9 \sigma_{g}$ ), and 41 classes for the adjusted phenotype (from $-3.9 \sigma_{g}$ to $+3.9 \sigma_{g}$ ). In contrast with the use of adjusted phenotypes (or EBVs or residuals) as continuous variables, such a transformation into classes allows an analysis without any extra assumption on the form of the relationship between type traits and longevity. Table I presents the description of each type trait, the beginning of scoring, and the minimum and the maximum number of animals in the UPRA and NON UPRA populations for adjusted phenotypes.

\subsection{Methods}

The reference model for the analysis of LPL was similar to the one used for the genetic evaluation in France [9], including the same environmental effects, but excluding the sire effect. This insures that the genetic component of type is not concurrently removed from the analysis when studying the influence of the adjusted phenotype on longevity.

In addition, some cows had been culled before having the opportunity to be type scored. For these cows, culling may or may not have been caused by their type characteristics. If this was the case, the fact that they were not scored would apparently increase the culling risk. To check this, an indicator variable of "presence $(=1)$ or absence $(=0)$ " of type score was added to the reference model. The hazard function $h(t)$ of a cow, $t$ days after her first calving, was defined as:

$$
h(t)=h_{0}(t) \exp \left\{\mathbf{x}^{\prime}(t) \boldsymbol{\beta}+\mathbf{z}^{\prime}(t) \boldsymbol{\delta}+p_{s}\right\}
$$

where $\boldsymbol{\beta}$ and $\boldsymbol{\delta}$ are matrices of incidence; $h_{0}(t)=\lambda \rho(\lambda t)^{\rho-1}$ is the Weibull baseline hazard function. The exponential term included:

- The time-dependent environmental effects $\mathbf{x}^{\prime}(t)$ of the national evaluation model, i.e.:

- a year * season effect with changes on March 1st and December 1st each year;

- the combined effect of lactation number ( 6 classes) with stage of lactation, $t^{\prime}$ days after each calving (with $t^{\prime}=30,60,150$ and 240 days);

- the combined effect of stage of lactation $*$ year $*$ season;

- the combined effect of the herd size (less than 5 cows, 5 to 20,20 to 50 and more than 50 cows) and of the variation in herd size from one year to the next $(-15 \%,-5 \%$ to $-15 \%$, stability, $+5 \%$ to $+15 \%$, and more than $15 \%)$, with changes on March 1st and December 1st each year;

- the random (log-gamma distributed) herd * year * season effect with changes on March 1st and December 1st each year. 
Table I. Type traits description, beginning of scoring and minimum and maximum number of animals for each type trait in the UPRA and NON UPRA populations for adjusted phenotypes.

\begin{tabular}{|c|c|c|c|c|}
\hline \multirow[t]{2}{*}{ Trait (abbreviation) } & \multirow[t]{2}{*}{$\begin{array}{l}\text { Type traits scored } 1 \text { to } 9 \\
\text { (except MS, TE: } 1 \text { to } 5 \text { ) }\end{array}$} & \multirow[t]{2}{*}{ Scored since } & \multicolumn{2}{|c|}{$\begin{array}{l}\text { Number of animals } \\
\text { (min/max) for adjusted } \\
\text { phenotypes }\end{array}$} \\
\hline & & & UPRA & NON UPRA \\
\hline Milking speed (MS) & Slow $\rightarrow$ fast & 1992 & $361 / 8077$ & $137 / 4734$ \\
\hline Udder cleft (UC) & Absent $\rightarrow$ deep & 1992 & $395 / 5284$ & $191 / 2940$ \\
\hline Udder depth (UD) & Low $\rightarrow$ high & 1992 & $296 / 6513$ & $96 / 3899$ \\
\hline Udder balance (UB) & Low rear $\rightarrow$ high rear & 1992 & $345 / 6342$ & $129 / 3691$ \\
\hline Distance between teats (DT) & Close $\rightarrow$ apart & 1992 & $498 / 6344$ & $287 / 3192$ \\
\hline Teat placement front (TPF) & Close $\rightarrow$ apart & 1992 & $554 / 5140$ & $233 / 2996$ \\
\hline Teat direction rear (TDR) & Internal $\rightarrow$ external & 1992 & $521 / 4360$ & $315 / 2398$ \\
\hline Teat length (TL) & Short $\rightarrow$ long & 1992 & $420 / 6849$ & $187 / 3766$ \\
\hline Rear udder attachment (RUA) & High $\rightarrow$ low & 1993 & $544 / 2817$ & $295 / 1903$ \\
\hline Fore udder attachment (FUA) & Short $\rightarrow$ long & 1996 & $115 / 998$ & $58 / 594$ \\
\hline Height at sacrum (HS) & Short $\rightarrow$ tall & 1992 & $322 / 4845$ & $216 / 2694$ \\
\hline Chest depth (CD) & Shallow $\rightarrow$ deep & 1992 & $414 / 5174$ & $181 / 2881$ \\
\hline Rump length (RL) & Short $\rightarrow$ long & 1992 & $387 / 5062$ & $216 / 2743$ \\
\hline Rump width (RW) & Narrow $\rightarrow$ wide & 1992 & $373 / 5226$ & $193 / 2887$ \\
\hline Rump angle (RA) & High pins $\rightarrow$ low pins & 1992 & $300 / 8991$ & $186 / 4588$ \\
\hline Rear leg set (RLS) & Sickled $\rightarrow$ straight & 1992 & $909 / 14455$ & $420 / 5708$ \\
\hline Heel depth (HD) & Shallow $\rightarrow$ deep & 1993 & $560 / 8142$ & $397 / 6076$ \\
\hline Temperament (TE) & Nervous $\rightarrow$ quiet & 1996 & $169 / 2034$ & $104 / 1290$ \\
\hline
\end{tabular}


The Weibull shape parameter $\rho$ was fixed to 2 . On the one hand, there is no loss of generality in doing so: when the Weibull baseline hazard function is combined with time-dependent covariates such as the interaction between stage of lactation and lactation number, the resulting hazard function is virtually identical whatever the value of $\rho$ in a wide range around 2 [9]. On the other hand, fixing $\rho$ considerably reduces computing costs.

- The time-dependent effects $\mathbf{z}^{\prime}(t)$ of production traits, i.e. the effects of milk production, fat and protein content, as deviation to herd-year average (separating first and later lactation), and distributed respectively in 10, 5 and 5 classes.

These latter effects were included as adjustment factors only for the analysis of approximate functional longevity. They were ignored for the true longevity analysis.

- The effect $p_{s}$ of presence/absence of type information. Since some type traits were introduced after 1992 (see Tab. I), this effect was defined accordingly for each group of trait(s). This effect was necessary to avoid restriction to cows with type information. Excluding cows without type records could result in biases and loss of accuracy if type information was missing.

The phenotypic (or the genetic or the residual) effect of each type trait $i$ was studied by adding the effect $m_{i j}$ of each class $j$ to this reference model. Then, the model was written:

$$
h(t)=h_{0}(t) \exp \left\{\mathbf{x}^{\prime}(t) \boldsymbol{\beta}+\mathbf{z}^{\prime}(t) \boldsymbol{\delta}+p_{s}+m_{i j}\right\} .
$$

Systematic scoring of fore udder attachment and temperament is recent in France. Few scored cows have been culled since their introduction. This negatively influences the accuracy of point estimates and of tests for these two traits.

For each population, for both longevity traits and for each description (phenotypic, genetic or residual) of type, likelihood ratio tests comparing model (2) (full model) and model (1) (reduced model) were performed in order to reveal which type traits statistically influenced longevity. Likelihoods were calculated, integrating out the herd-year-season random effects. Because all these test statistics had the same number of degrees of freedom, their magnitude also brought information on the relative importance of each trait.

For a better display of the relationship between each type trait and longevity, the relative risks $\exp \left\{\hat{m}_{i j}\right\}$ were plotted as a function of adjusted phenotypic scores, or EBVs, or residuals (by step of $0.2 \sigma_{g}$ ). From these estimates $\hat{m}_{i j}$, expected survival curves were computed for "standard" animals, differing only in their phenotype for type traits. The common environmental characteristics considered were: constant calving interval of $365 \mathrm{~d}$, average within-herd relative production of milk, fat and protein, average age at first calving and average herd $*$ year $*$ season effect. These expected curves help to quantify the effects of type on longevity for a cow in average environmental conditions.

Because the relationship between type traits and longevity is often nonlinear, we attempted to depict this more precisely. This was done performing a weighted regression of the estimates $\hat{m}_{i}$ on classes of adjusted phenotype for the considered type trait. The weights were the inverse of the asymptotic error variances supplied by the "Survival Kit". We also checked, in a previous 
analysis not presented here, that this approach gave results almost identical to a direct analysis treating adjusted phenotype $\hat{m}_{i j}$ in (2) (and its square, etc.) as a continuous covariate. This two-step procedure was preferred to the (equivalent) direct analysis because the $\hat{m}_{i j}$ 's were already available, leading to a huge reduction in computing costs.

So far, we did not intend to quantify the proper effect of each type trait independently from the others. Indeed, some type traits (e.g., udder traits) are moderately to highly correlated one to the other. Then, one may wonder whether some of these traits do not influence longevity per se but appear important only because of these correlations with athers. In order to quantify how much extra information is brought by each trait as an explanatory factor of longevity, a stepwise regression analysis was performed treating adjusted phenotypes as continuous variables. This was done in the NON UPRA population, considering both true and functional longevities. The initial model was the one including the type trait with the largest effect (largest contribution to the likelihood) for true as well as for functional longevity. Then, at each step, the linear (or quadratic or cubic) effect of each trait was added and only the term with the largest (significant) effect was retained for the next step. This procedure was arbitrarily stopped when the sequential contribution of a new trait became lower than 0.1 times the contribution of the most important type trait influencing true longevity. This does not preclude the effect of other type traits to be significant but their interest as early predictors would be greatly reduced.

\section{RESULTS}

\subsection{Effect of absence of type information}

Whatever the population considered, the culling risk of a cow which was not type scored was significantly increased. The relative risk (RR), defined as $\exp \left\{\hat{p}_{s}\right\}$, represented the factor by which culling risk of cows not scored was increased (if $R R>1$ ) or decreased (if $R R<1$ ) with respect to a scored animal. This risk factor was 2.15 for the registered (UPRA) population and only 1.17 for the nonregistered animals. These estimates were unchanged when a correction for production traits was added. In the UPRA population, all first lactation cows were classified and therefore, no sampling was involved: it can be concluded that in most cases, a cow without type information was voluntarily or involuntarily culled very early, possibly based on type before the yearly visit of the UPRA technician. Consequently, the effect of type on longevity that was obtained from the survival analysis was likely to underestimate the true effect. In the NON UPRA population, this phenomenon may exist, but since first lactation cows were not exhaustively classified, the sampling of herdmates for the type evaluation led to an important "dilution" of the effect of the absence of scoring.

\subsection{Effect of type adjusted phenotype on longevity}

The contributions to the likelihood $(\times 2)$ of each type trait adjusted phenotype are shown in Figures 1 and 2 for the NON UPRA and UPRA populations 


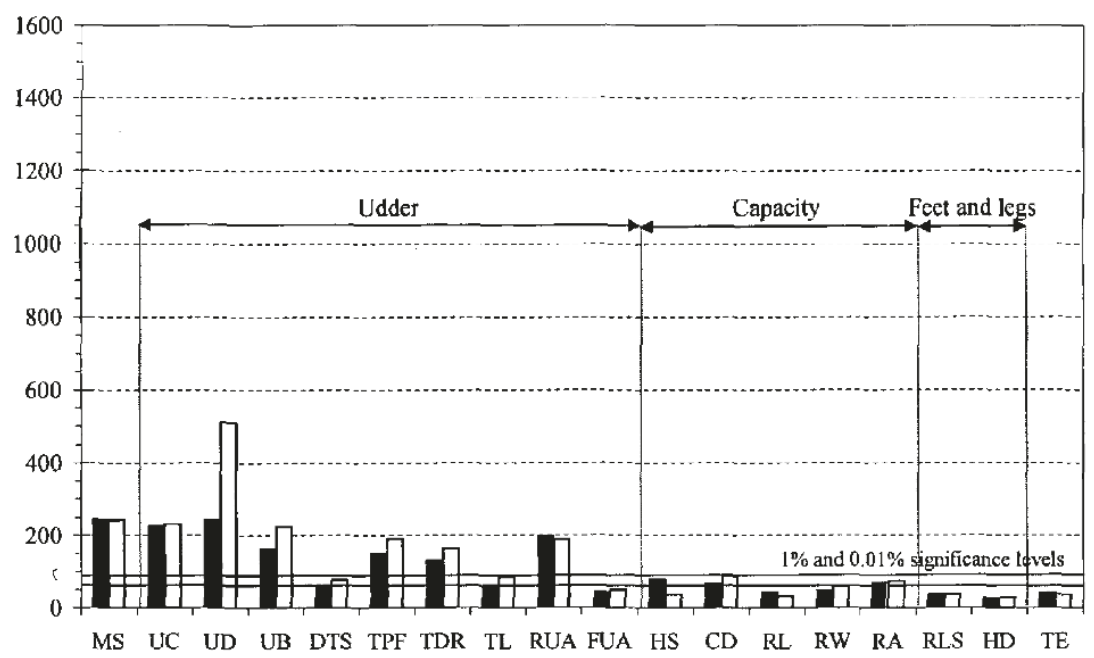

Figure 1. Contribution to the likelihood $(\times 2)$ of adjusted phenotype for type traits on length of productive life: NON UPRA population (without (in black) and with (in white) correction for production). See Table I for trait abbreviations.

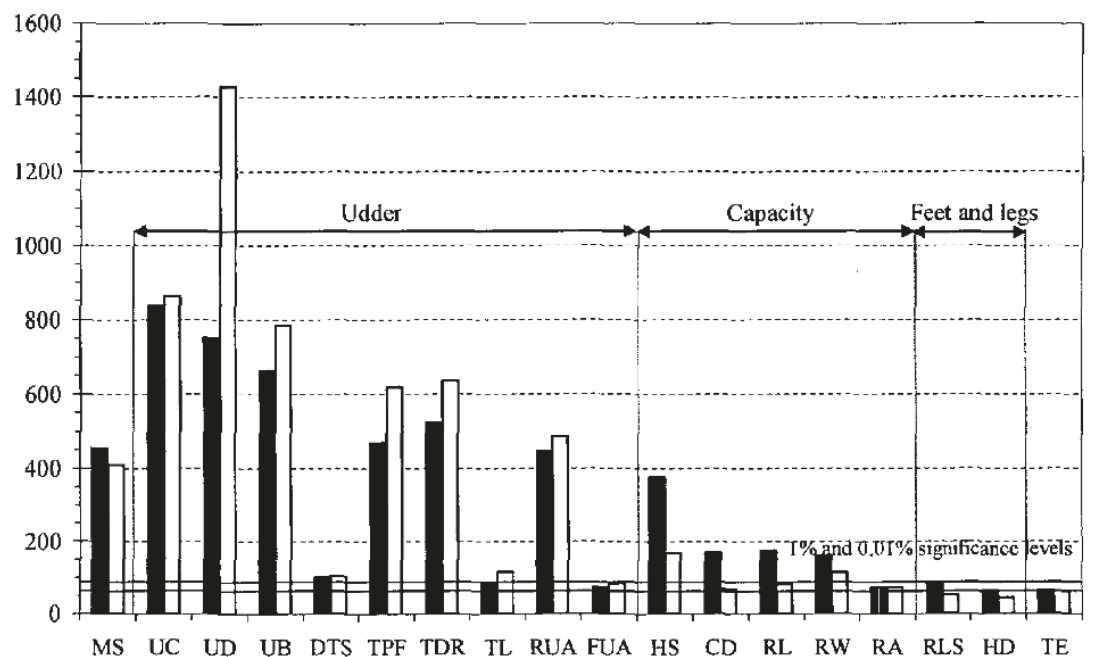

Figure 2. Contribution to the likelihood $(\times 2)$ of adjusted phenotype for type traits on length of productive life: UPRA population (without (in black) and with (in white) correction for production). See Table I for trait abbreviations.

respectively, and they can be compared to the $1 \%$ and $0.01 \%$ significance levels for a $\chi^{2}$ test with 40 degrees of freedom.

\subsubsection{Comparison between UPRA and NON UPRA populations}

Whether culling risk was adjusted for production traits or not, udder traits as well as milking speed were the most important traits. They were all significant 
at the $0.01 \%$ level, cxcept teat distance (side view) and fore udder attachment in the NON UPRA population (it should be remembered, however, that data availability on fore udder attachment was too recent to really be informative). Clearly, the impact of these traits on longevity was much higher in the UPRA population. Also, all traits related to udder support (udder cleft, udder depth, udder balance and rear udder attachment) better explained culling risk differences than traits related to teat length and placement.

The effect of capacity traits on true longevity was significant in the UPRA population (although much less prominently than for udder traits) but not in the NON UPRA population.

Feet and legs traits (rear leg set and heel depth) had no significant effect on true longevity in the NON UPRA population and their impact was barely significant in the UPRA population.

Temperament, as for fore udder attachment, was penalised by a lack of information, due to its recent addition to the scoring list.

\subsubsection{Comparison between true and functional longevity}

Overall, the importance of udder traits in explaining longevity was increased when production was corrected for. This was especially true for udder depth in both subpopulations: deep udders are more frequent among high yielding cows, which were less often voluntarily culled. As a result, the effect of udder depth was reduced when production was not accounted for.

In contrast, for capacity traits, including an adjustment for production decreased the importance of the traits (except for chest depth, rump width and rump angle among NON UPRA cows). These traits are often considered as being favourably correlated to milk production. Tall and deep cows often have higher production, which to some extent, protect them against voluntary culling. After correction, these traits did not contribute as much as previously to longevity. However, they remained more important (significant) in the UPRA population. This might indicate a particular attitude of UPRA breeders towards capacity traits, with some voluntary culling on such traits.

\subsubsection{Estimates of relative risk}

Figures 3 to 6 present the relative risks $\exp \left\{\hat{m}_{i}\right\}$ plotted as function of the classes of adjusted phenotypic score (by step of $0.2 \sigma_{g}$ ) for udder depth in the NON UPRA population (Figs. 3 and 4) and in the UPRA population (Figs. 5 and 6), for the true and functional longevity analyses, respectively. All estimates are compared to class " 0 " $\left(0.1\right.$ to $\left.+0.1 \sigma_{g}\right)$.

As an illustration, let us take the phenotypic class "-8": it corresponds to scores adjusted for environmental effects between $-1.7 \sigma_{g}$ and $-1.5 \sigma_{g}$, i.e., raw values between -0.82 and $-0.72\left(\sigma_{g}=0.4803\right.$ for udder depth) with respect to the reference value $(\hat{g}+\hat{r}=0)$. In the NON UPRA population, the relative culling risk for an animal in this class was $\exp \left\{\hat{m}_{i}\right\}=1.05$ for true longevity and 1.12 for functional longevity. In the UPRA population, these values were higher: 1.16 for true longevity and 1.24 for functional longevity. 
Figures 3 to 6. Relative culling risk as a function of class of udder depth adjusted phenotype, from very deep (class -20 ) to very shallow (class +20 ) udders (reference $=$ class " 0 "; dotted lines $=95 \%$ confidence interval, class width: 0.2 genetic standard deviation).

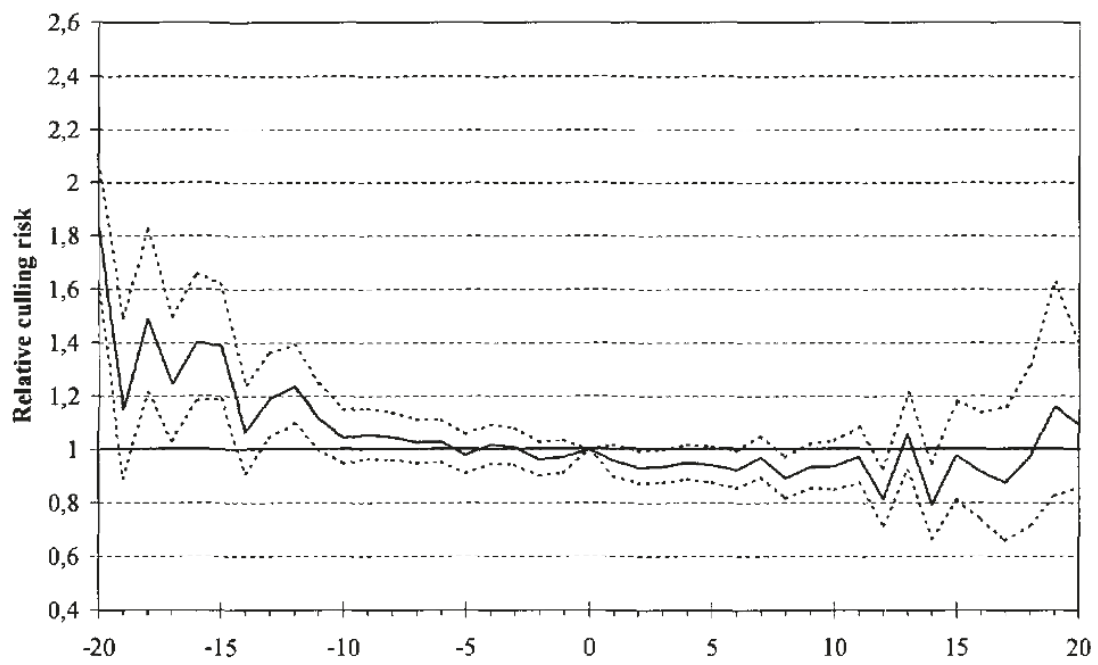

Figure 3. NON UPRA data set, true longevity.

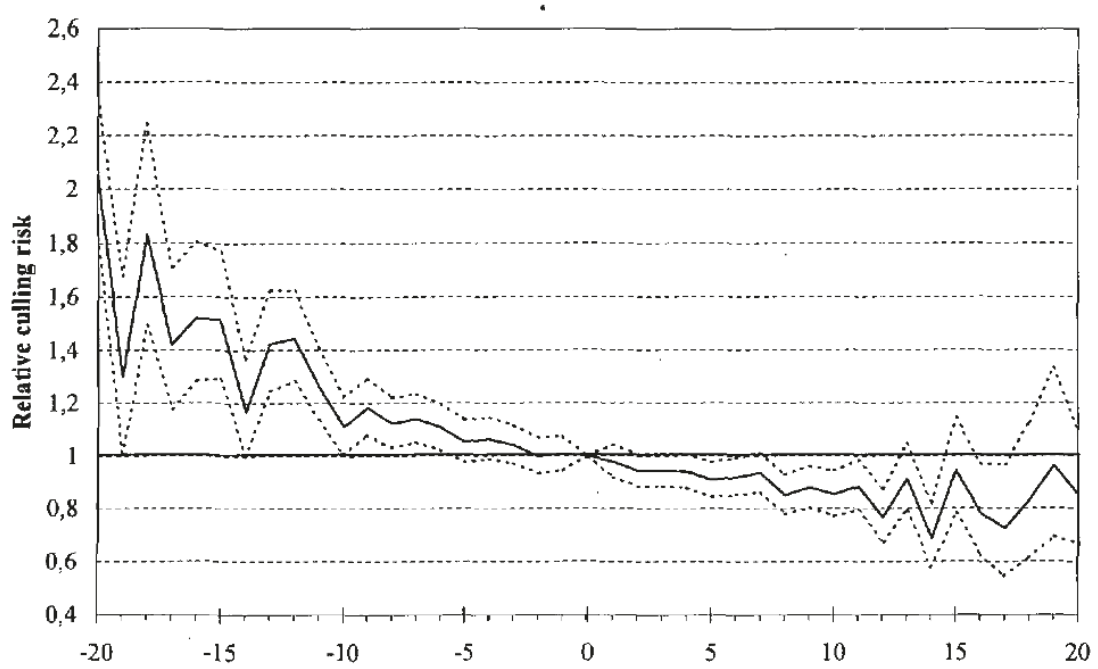

Figure 4. NON UPRA data set, functional longevity.

A $95 \%$ confidence interval for each estimate is also displayed on these figures. The rather erratic variations of estimates for extreme classes were due to a lower number of animals in each class, which resulted in a larger confidence interval. 


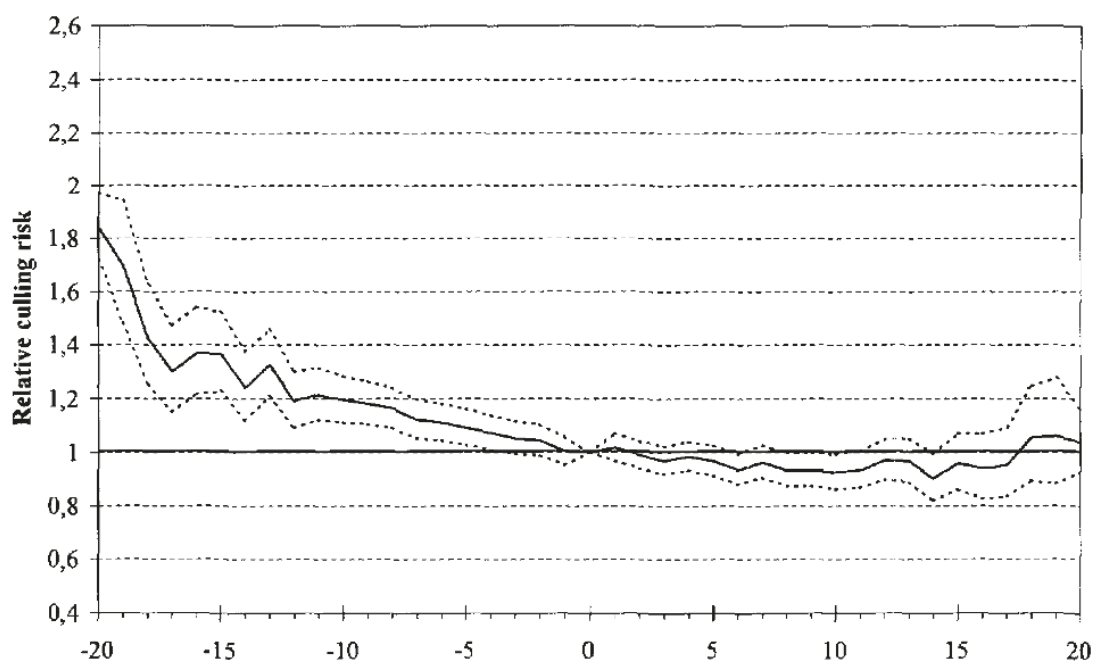

Figure 5. UPRA data set, true longevity.

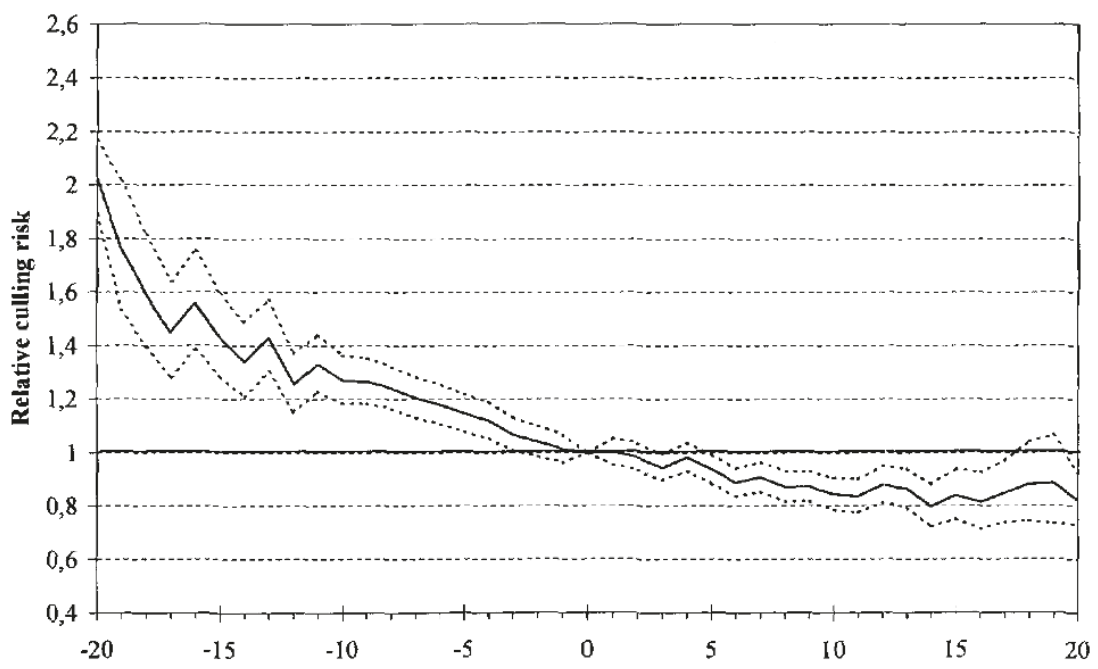

Figure 6. UPRA data set, functional longevity.

Again, it can be seen that udder depth was more important in the UPRA population and/or when production traits were adjusted for: then, the relative risk curves were somewhat steeper when udder depth got worse.

\subsubsection{Quantifying the effect of type traits on longevity}

Figures 7 and 8 present the change in the expected length of life of cows with different udder depth phenotypes. All calculations were done assuming a reference cow in average environmental conditions and with constant lactation 


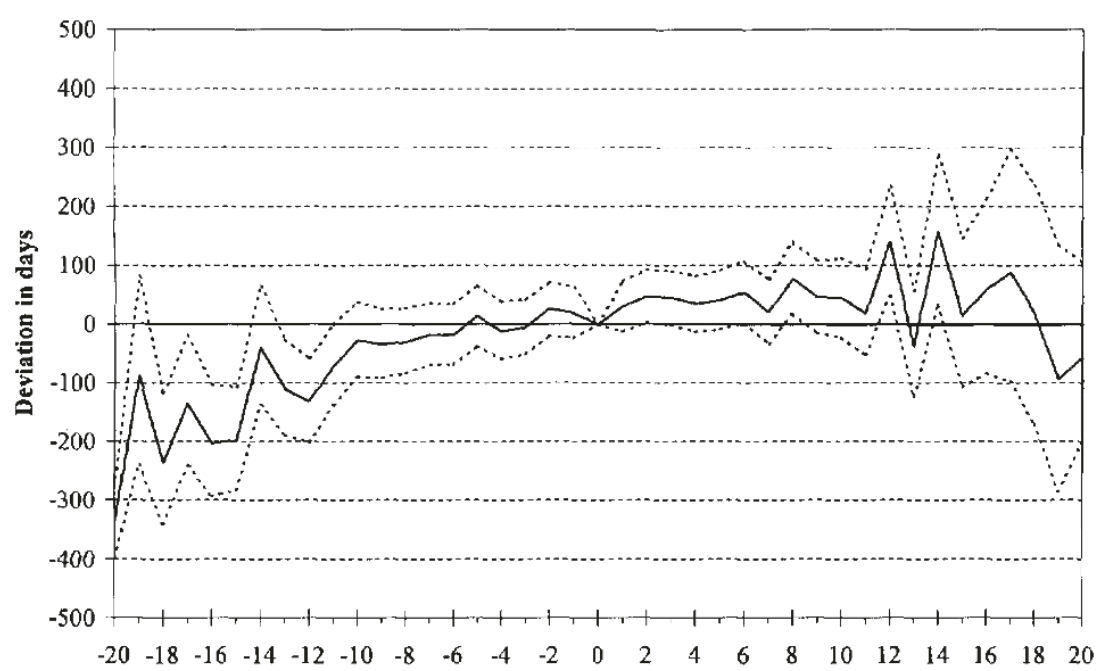

Figure 7. Change in expected length of life as a function of the class of udder depth adjusted phenotype: NON UPRA population (Reference: class "0"; dotted lines $=$ approximate $95 \%$ confidence interval based on each class estimate \pm twice its standard error).

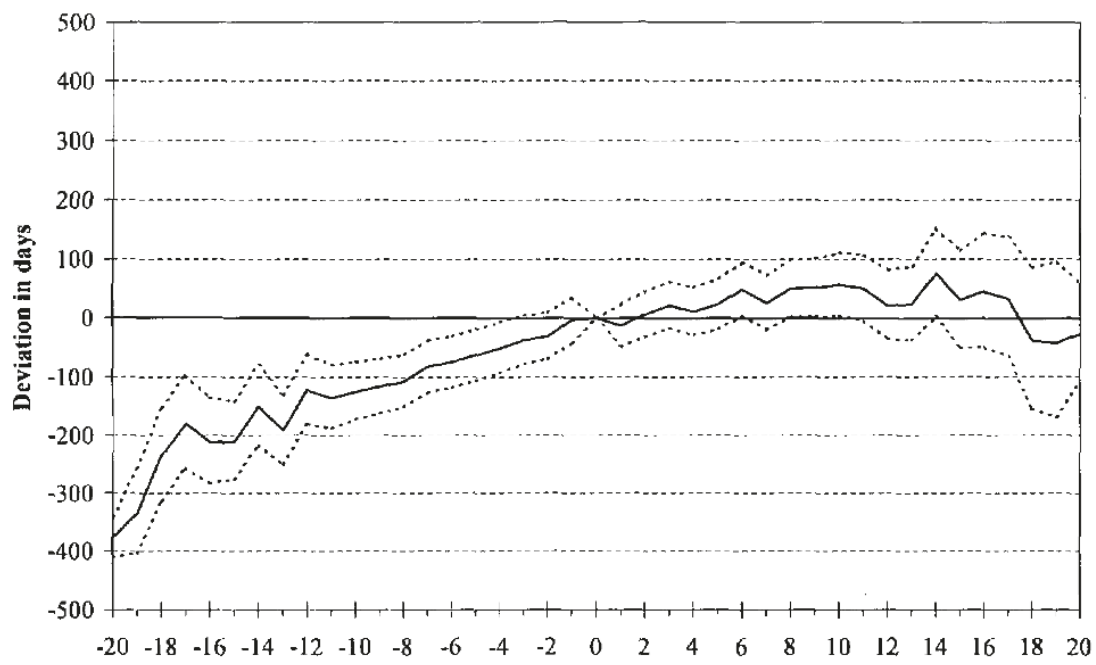

Figure 8. Change in the expected length of life as a function of the class of udder depth adjusted phenotype: UPRA population (Reference: class " 0 "; dotted lines = approximate $95 \%$ confidence interval based on each class estimate \pm twice its standard error).

length (305 d) and calving interval (365 d). These changes were expressed with respect to the average (" 0 ") class. For example, a cow with an udder depth scoring in the " -8 " class in an UPRA herd was expected to live 107 days less 


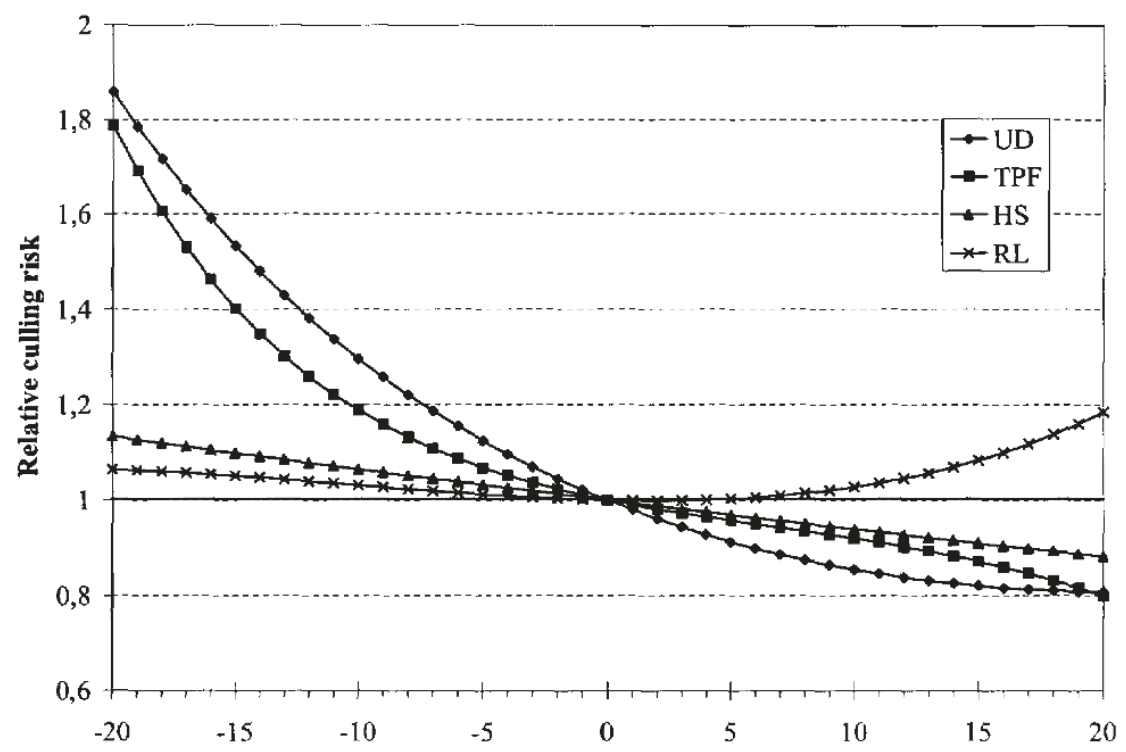

Figure 9. Relative culling risk as a function of adjusted phenotype, obtained after regression of $\hat{m}_{i}$ estimates on class of adjusted phenotype (UPRA population; functional longevity). UD: Udder depth; TPF: Teat placement front (in the way: apart $\rightarrow$ close); HS: Height at sacrum; RL: Rump lenght.

than a cow in class " 0 ". The corresponding figure for a NON UPRA herd was only 30 days. This reflects once more the larger importance of type in UPRA herds.

\subsubsection{Form of the relationship between type traits and longevity}

The previous curves showed that the relationship between type traits and longevity was often nonlinear. To depict it more accurately, a weighted regression of the estimates $\hat{m}_{i}$ on classes of adjusted phenotype was performed. Plots of relative risks of adjusted phenotypes were obtained, and are shown in Figure 9 for functional longevity in the UPRA population.

For all udder traits, quadratic terms were always significantly different from 0 , whatever the population studied.

For some traits, in particular teat placernent front and teat direction rear, the cubic term was also significant, reflecting a different behaviour on the two extreme directions (for example a rather "flat" risk on one end).

For capacity traits, a polynomial regression of $\hat{m}_{i}$ on classes of adjusted phenotype gave a poorer fit. Significant quadratic terms were found in the UPRA population and only for true longevity in the NON UPRA herds. Even the linear coefficients were barely significant for feet and legs. 


\subsubsection{Relative importance of type traits}

The initial model for the stepwise regression was the one including the type trait with the largest effect (largest contribution to the likelihood) as observed in Figure 1: milking speed for the true longevity model and udder depth for the functional longevity one.

Tables II and III present the regression coefficients and the contribution of type traits in the final model (respectively for true and functional longevity) in the NON UPRA population, in the order of inclusion.

Again, the main role of milking speed and udder traits was striking. Note that the combined effect of udder depth and milking ease (i.e., the sum of their linear and quadratic contributions to the likelihood) accounted for $84 \%$ of the total contribution of type traits on functional longevity.

In Figure 1, whereas virtually all udder traits were found to have a significant effect, only udder depth, udder cleft and rear udder attachment appeared to be directly related to true longevity here. Even though udder depth and udder cleft were moderately correlated, their influence on longevity was different. For both measures of longevity, quadratic terms for udder traits and milking speed were significantly different from 0 , as was already found for udder depth in section 3.2.5.

Also, rump angle significantly influenced both true and functional longevity, steeper rumps being more favourable. With the correction for milk production, height at sacrum disappeared as an important type trait influencing functional longevity, whereas the chest depth coefficient became significantly different from 0: deeper chests were unfavourable. For all these traits (except rump angle, in the functional longevity case), quadratic terms were not significant.

\subsection{Effect of type genotype and residual on longevity}

Figures 10 to 13 show the contribution to the likelihood of each type trait genotype (Figs. 10 and 11) and each type trait residual (Figs. 12 and 13), for the NON UPRA and UPRA populations, respectively.

The contribution of genotype was much larger than the contribution of residuals. EBV classes explain a larger part of the relationship between type and longevity than phenotypic classes. In fact, a comparison of the two types of models, for example based on the Akaike information criterion (AIC), would consider the model with genotype as better in most cases. But overall, the same comments can be made:

- virtually all type traits were important in UPRA herds;

- udder traits and milking ease were important for longevity, whatever the population considered;

- capacity (size) traits did not influence longevity in the NON UPRA population and their importance was decreased in the UPRA population when production was adjusted for.

The residuals had little impact and the AIC value for the corresponding models was much worse than for the models which included type traits either as classes of adjusted phenotype or genotype. Residuals seemed to introduce "background 
Table II. Partial regression coefficient estimates and sequential and marginal contributions to the likelihood of type traits for true longevity, in the NON UPRA population.

\begin{tabular}{|c|c|c|c|c|c|c|}
\hline Type Trait ${ }^{\mathrm{a}}$ & Description & Form $^{b}$ & $\begin{array}{l}\text { Partial } \\
\text { regression } \\
\text { coefficient }\end{array}$ & $\begin{array}{l}\text { Standard } \\
\text { error }\end{array}$ & $\begin{array}{l}\text { Sequential } \\
\text { contribution to } \\
\text { the likelihood }^{\mathrm{c}}\end{array}$ & $\begin{array}{l}\text { Marginal } \\
\text { contribution to } \\
\text { the likelihood }\end{array}$ \\
\hline MS & slow $\rightarrow$ fast & $\mathrm{L}$ & -0.0349 & 0.0040 & 159.0 & 76.5 \\
\hline UC & absent $\rightarrow$ deep & $\mathrm{L}$ & -0.0282 & 0.0037 & 122.5 & 58.0 \\
\hline RUA & low $\rightarrow$ high & $\mathrm{L}$ & -0.0235 & 0.0038 & 68.3 & 38.9 \\
\hline UD & low $\rightarrow$ high & $\mathrm{L}$ & -0.0190 & 0.0048 & 37.1 & 15.8 \\
\hline UD & low $\rightarrow$ high & $Q$ & 0.0152 & 0.0022 & 53.5 & 49.8 \\
\hline $\mathrm{RA}$ & high pins $\rightarrow$ low pins & $\mathrm{L}$ & -0.0175 & 0.0040 & 27.1 & 18.7 \\
\hline RUA & low $\rightarrow$ high & $\mathrm{Q}$ & 0.0071 & 0.0015 & 21.7 & 22.2 \\
\hline HS & short $\rightarrow$ tall & $\mathrm{L}$ & -0.0156 & 0.0037 & 17.8 & 17.8 \\
\hline
\end{tabular}

a Type traits are presented in the order as they appear in the stepwise regression procedure.

b $\mathrm{L}=$ linear; $\mathrm{Q}=$ quadratic.

c Increase in $-2 \log$ likelihood when the effects are sequentially added to the model in the order specified in the table.

d Increase in $-2 \log$ likelihood when the full model is compared to a reduced model deleting this effect.

Trait abbreviations: see Table I. 
Table III. Partial regression coefficient estimates and sequential and marginal contributions to the likelihood of type traits for functional longevity, in the NON UPRA population.

\begin{tabular}{|c|c|c|c|c|c|c|}
\hline Type Trait $^{a}$ & Description & Form $^{b}$ & $\begin{array}{l}\text { Partial } \\
\text { regression } \\
\text { coefficient }\end{array}$ & $\begin{array}{l}\text { Standard } \\
\text { error }\end{array}$ & $\begin{array}{l}\text { Sequential } \\
\text { contribution to } \\
\text { the likelihood }{ }^{c}\end{array}$ & $\begin{array}{l}\text { Marginal } \\
\text { contribution to } \\
\text { the likelihood }^{\mathrm{d}}\end{array}$ \\
\hline UD & low $\rightarrow$ high & $\mathrm{L}$ & -0.0757 & 0.0046 & 419.7 & 266.6 \\
\hline MS & slow $\rightarrow$ fast & $\mathrm{L}$ & -0.0305 & 0.0040 & 99.7 & 57.6 \\
\hline MS & slow $\rightarrow$ fast & $\mathrm{Q}$ & 0.0110 & 0.0017 & 48.3 & 42.8 \\
\hline UD & low $\rightarrow$ high & $\mathrm{Q}$ & 0.0108 & 0.0022 & 36.6 & 24.8 \\
\hline $\mathrm{CD}$ & shallow $\rightarrow$ deep & $\mathrm{L}$ & 0.0208 & 0.0038 & 28.9 & 29.9 \\
\hline UC & absent $\rightarrow$ deep & $\mathrm{L}$ & -0.0167 & 0.0037 & 27.2 & 20.2 \\
\hline $\mathrm{RA}$ & high pins $\rightarrow$ low pins & $\mathrm{L}$ & -0.0174 & 0.0039 & 19.7 & 19.7 \\
\hline $\mathrm{UC}$ & absent $\rightarrow$ deep & $\mathrm{Q}$ & 0.0069 & 0.0016 & 19.5 & 18.9 \\
\hline RA & high pins $\rightarrow$ low pins & $\mathrm{Q}$ & 0.0070 & 0.0016 & 18.2 & 18.5 \\
\hline
\end{tabular}

a Type traits are presented in the order as they appear in the stepwise regression procedure.

${ }^{\text {b }} \mathrm{L}=$ linear; $\mathrm{Q}=$ quadratic.

${ }^{c}$ Increase in $-2 \log$ likelihood when the effects are sequentially added to the model in the order specified in the table.

${ }^{d}$ Increase in $-2 \log$ likelihood when the full model is compared to a reduced model deleting this effect.

Trait abbreviations: sce Table I. 


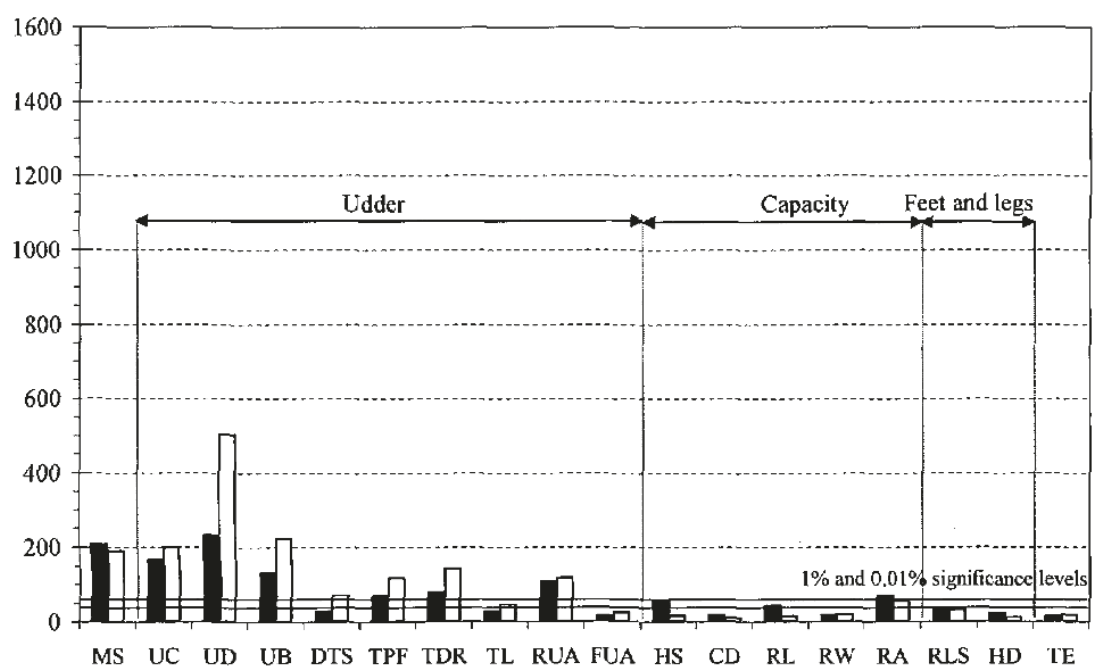

Figure 10. Contribution to the likelihood $(\times 2)$ of type traits genotype on length of productive life: NON UPRA population (without (in black) and with (in white) correction for production). See Table I for trait abbreviations.

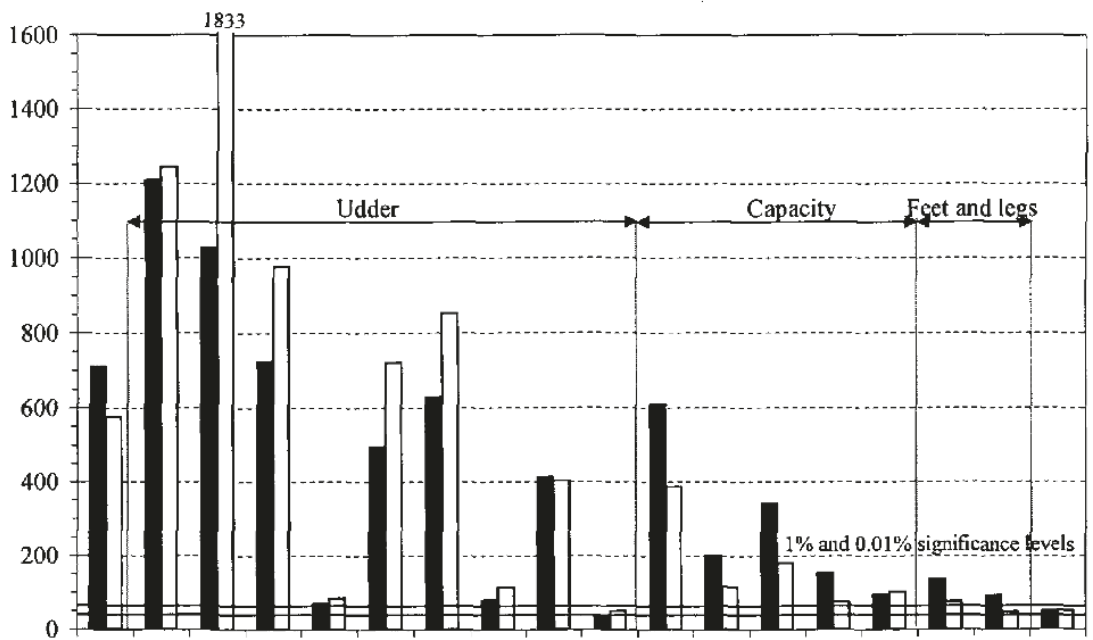

MS UC UD UB DTS TPF TDR TL RUA FUA HS CD RL RW RA RLS HD TE

Figure 11. Contribution to the likelihood $(\times 2)$ of type traits genotype on length of productive life: UPRA population (without (in black) and with (in white) correction for production). See Table I for trait abbreviations.

noise" which, for udder depth for example, led to a larger contribution of the genotype in comparison to the adjusted phenotype. For capacity traits, the plots of relative risks for the genotype and the residual were in the opposite direction; animals genetically high had a lower risk to be culled, whereas those "residually" high had a higher risk to be culled. 


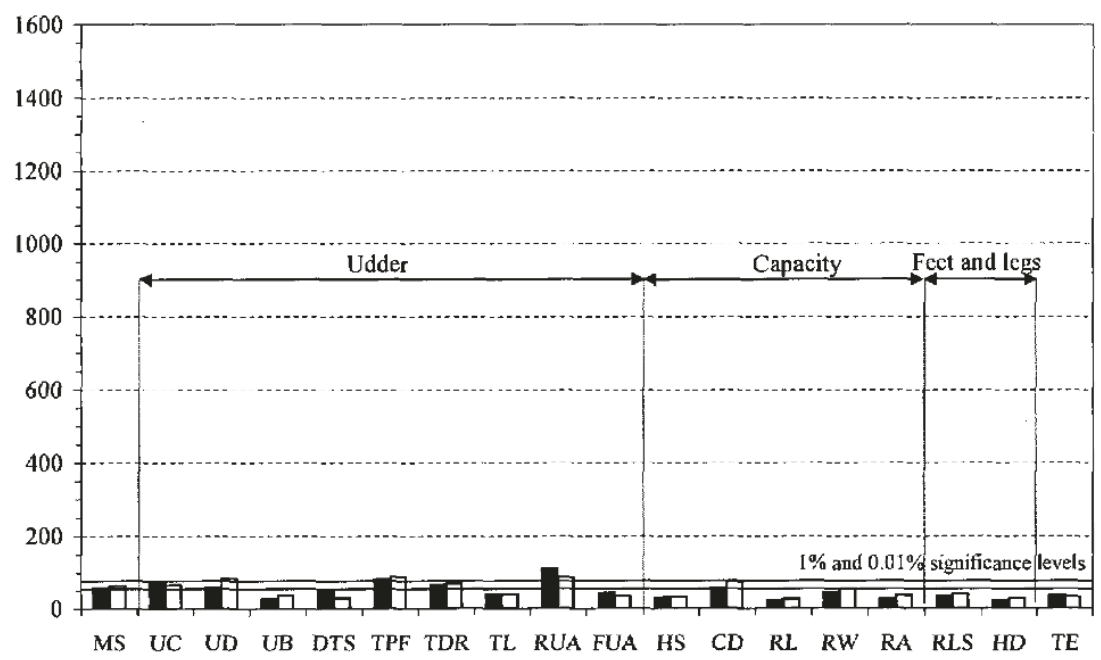

Figure 12. Contribution to the likelihood $(\times 2)$ of type traits residual on length of productive life: NON UPRA population (without (in black) and with (in white) correction for production). See Table I for trait abbreviations.

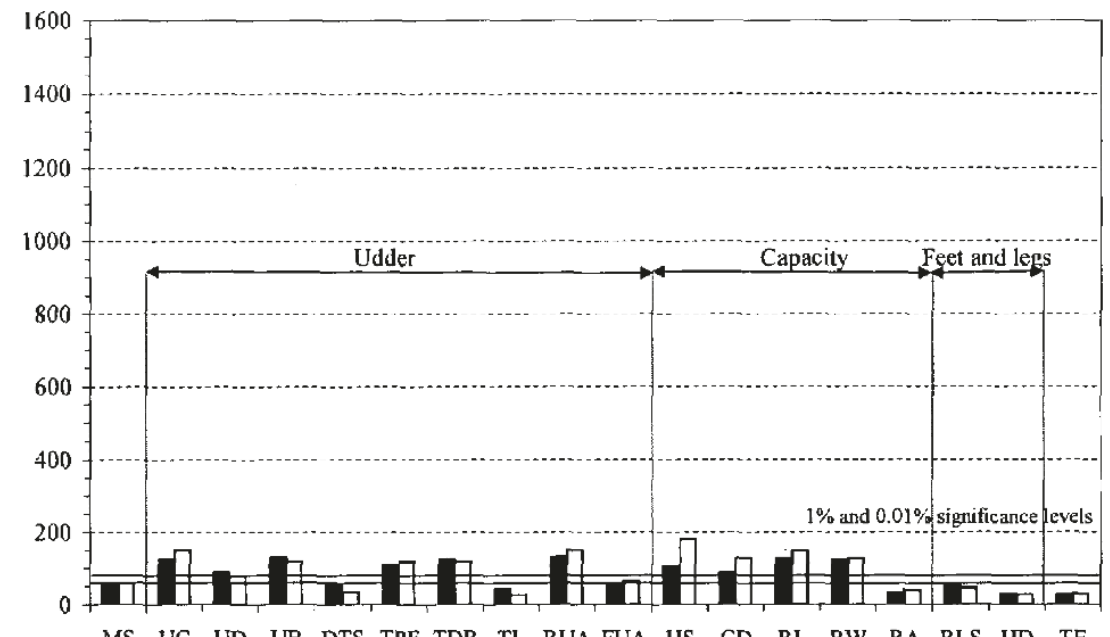

Figure 13. Contribution to the likelihood $(\times 2)$ of type traits residual on length of productive life: UPRA population (without (in black) and with (in white) correction for production). See Table I for trait abbreviations.

Because we used adjusted phenotypes, the residual part only represents within herd-year environmental differences for type. It seems that this part is much less important for the prediction of longevity than the genotype or (probably) the across-herd environmental differences. 


\section{DISCUSSION}

As in many other studies, we demonstrated that udder traits have the largest influence on functional longevity. We found however that in the French Holstein breed, teat traits were not as important as usually found in the literature. This is especially true for distance between teats and teat length, for which the effects on longevity were barely significant. Other authors, such as Vollema [18] or Sölkner [16] have found that teat length has a relatively strong relationship with functional longevity in their populations: cows with the longest teats have the highest risk of being culled. One might consider that the genetic level of these traits, in the French Holstein breed, was already acceptable.

In the same way, we did not find any strong relationship between feet and legs traits and functional longevity. Bünger and Swalve [3] found a relatively large contribution of rear legs (side view) and foot angle to likelihood. Other studies (see [18] for a review) found moderate genetic and phenotypic correlations between feet and legs traits and functional longevity (not studied through a survival analysis). For Dekkers et al. [4] and Vollema [18], a composite trait or a subjective score for feet and legs were more strongly related with functional longevity than basic traits. In France, it seems that there are two limitations with the way feet and legs traits are presently recorded. Firstly, they appear difficult to score by technicians, especially for heel depth. In the French Montbéliarde breed, Robert-Granié et al. [13] found that technicians were not scoring feet and legs traits homogeneously. Secondly, the choice of these two feet and legs traits seems inadequate to correctly describe the way a cow walks. With the hope that feet and legs description as functional traits gets improved, the French Holstein UPRA decided to include a subjective locomotion score in the list of traits, starting on December 1st, 1999. Its interest as an early predictor of longevity remains to be shown.

Capacity traits had a different impact on the length of productive life in the two Holstein populations considered. After correction for milk production their effect remained significant for functional longevity in the UPRA population. This may be interpreted as an indication that UPRA breeders perform some voluntary culling on these traits. Such a conclusion would be consistent with other studies comparing registered and grade populations [14,15]. Bünger and Swalve [3] found, in a survival analysis, a significant contribution of capacity traits on functional longevity in a population somewhat similar to a registered one. They also found an intermediate optimum for stature, that we did not find.

The present study suggests that differences between the two breeder populations were not as pronounced in France as in the North American situation, for which for some traits, effects in opposite directions or of completely different orders of magnitude were found in the grade and registered populations (Ducrocq, unpublished results).

In the NON UPRA population, the effects of capacity traits on longevity were barely significant. Only height at sacrum had a slightly positive relationship with true longevity, probably due to the positive correlation between this type trait and milk production. After correction for milk production, the height at sacrum was no longer significant but the effect of chest depth became significant with a negative relationship with functional longevity: cows with large 
body depth had a higher risk to be culled. This is consistent with the results of Boettcher et al. [1] and Bünger and Swalve (personal communication). There may be a biological antagonism between functional longevity and deep chests.

\section{CONCLUSION}

In French Holstein herds, cows with a deep udder and slow milking were at higher risk. But registered (UPRA) breeders appeared as being more strict in their culling practices on type. For them, capacity traits also seemed to be considered in culling decisions, even after accounting for production. Because these results were not found in the NON UPRA population, it may be assumed that capacity traits were subject to some voluntary culling in the UPRA population. Then, in the registered breeders population, the relevance of production adjusted longevity as an approximation of functional longevity (defined as the ability to delay involuntary culling) may be questionable. A direct consequence of this is that a correct estimation of genetic correlations as a tool to find early predictors of longevity should be based on the nonregistered (NON UPRA) data. Unfortunately, type information is often scarce in this population.

Correction for production traits revealed some partly hidden relationships between type and longevity. This leads to an even higher contribution of udder traits and a reduction of the importance of traits positively correlated with production, such as some capacity traits.

As suspected, most type traits presented a nonlinear relationship with longevity. This nonlinearity was more marked for udder traits. However, quadratic or higher coefficients were relatively moderate and we did not find any trait with a clear intermediate optimum: the validity of genetic correlations computed assuming linearity between genetic components of type and longevity, should not be altered too much.

\section{ACKNOWLEDGEMENTS}

The authors would like to thank the reviewers and the editor.

\section{REFERENCES}

[1] Boettcher P.J., Jairath L.K., Koots K.R., Dekkers J.C.M., Effects of interactions betwcen type and milk production on survival traits of Canadian Holsteins, J. Dairy Sci. 80 (1997) 2984-2995.

[2] Brotherstone S., Hill W.G., Dairy herd life in relation to linear type traits and production. 2. Genetic analyses for pedigree and non-pedigree cows, Anim. Prod. 53 (1991) 289-297.

[3] Bünger A., Swalve H.H., Analysis of survival in dairy cows using supplementary data on type scores and housing systems, in: Proceedings of the 4th International Workshop on Genetic Improvement of Functional Traits in Cattle, Jouy-en-Josas, 1999, INTERBULL bulletin No. 21, Uppsala, pp. 104-110. 
[4] Dekkers J.C.M., Jairath L.K., Lawrence B.H., Relationships between sire genetic evaluations for conformation and functional herd life of daughters, J. Dairy Sci. 77 (1994) 844-854.

[5] Dentine M.R., Mc Daniel B.T., Norman H.D., Comparison of culling rates, reasons for disposal, and yields for registered and grade Holstein cattle, J. Dairy Sci. 70 (1987) 2616-2622.

[6] Ducrocq V., Genetic parameters for type traits in the French Holstein breed based on a multiple-trait animal model, Livest. Prod. Sci. 36 (1993) 143-156.

[7] Ducrocq V., Survival analysis, a statistical tool for longevity data, in: Proceedings of the 48th Annual Meeting of the European Association for Animal Production, Vienna, 1997, Wageningen Pers, Wageningen, 3:29 (abstract).

[8] Ducrocq V., Sölkner J., "The Survival Kit V3.0", a package for large analyses of survival data, in: Proceedings of the 6th World Congress on Genetics Applied to Livestock Production, 1998, Vol. 27, University of New England, Armidale, pp. 447-448.

[9] Ducrocq V., Sölkner J., Implementation of a routine breeding value evaluation for longevity of dairy cows using survival analysis techniques, in: Proceedings of the 6th World Congress on Genetics Applied to Livestock Production, 1998, Vol. 23, University of New England, Armidale, pp. 359-362.

[10] Dürr J.W., Genetic and phenotypic studies on culling in Quebec Holstein cows, Ph.D. Thesis, Mc Gill Univ., Montreal, 1997.

[11] Essl A., Fitness and longevity in animal breeding: a historical review, in: Proceedings of the 48th Annual Meeting of the European Association for Animal Production, Vienna, 1997, Wageningen Pers, Wageningen, 3:1 (abstract).

[12] Larroque H., Ducrocq V., An indirect approach for the estimation of genetic correlations between longevity and other traits, in: Proceedings of the 4th International Workshop on Genetic Improvement of Functional Traits in Cattle, Jouy-en-Josas, 1999, INTERBULL bulletin No. 21, Uppsala, pp. 128-135.

[13] Robert-Granié C., Ducrocq V., Foulley J.L., Heterogeneity of variance for type traits in the Montbeliarde cattle breed, Genet. Sel. Evol. 29 (1997) 545-570.

[14] Rogers G.W., Mc Daniel B.T., Dentine M.R., Johnson L.P., Relationships among survival rates, predicted differences for yield, and linear type traits, J. Dairy Sci. 71 (1998) 214-222.

[15] Short T.H., Lawlor T.J., Genetic parameters of conformation traits, milk yield, and herd life in Holsteins, J. Dairy Sci. 75 (1992) 1987-1998.

[16] Sölkner J., Petschina R., Relationship between type traits and longevity in Austrian Simmental cattle, in: Proceedings of the 49th Annual Meeting of the European Association for Animal Production, Warsaw, 1998, Wageningen Pers, Wageningen, 4:177 (abstract).

[17] Schneider M.P., Effects of type traits on herd life in Holstein cows, MSc. Thesis, Mc Gill Univ., Montreal, 1998.

[18] Vollema A.R., Selection for longevity in dairy cattle, Ph.D. Thesis, Animal Breeding and Genetics Group, Wageningen, 1998.

To access this journal on line: www.edpsciences.org 